\title{
O PLURALISMO DE SENTIDOS DA CULTURA DA MÍDIA CONTEMPORÂNEA ${ }^{1}$
}

\author{
João Montenegro da S. P. Reis ${ }^{2}$
}

\section{Resumo}

O artigo a ser apresentado consiste na análise dos filmes "O Senhor das Armas"; "Syriana" e "Diamante de Sangue,"três grandes produções dos estúdios de Hollywood. Tratam-se de produtos culturais da mídia, que estão francamente inseridos na lógica do mercado, mas cujo conteúdo, apesar do caráter apelativo, apresenta um poder de significação diversificado. Com base nos estudos culturais britânicos e nas análises multi-perspectívicas de Douglas Kellner, que utiliza recursos históricos e das teorias social e da comunicação, este trabalho propõe uma visão diferente quanto aos produtos culturais de massa contemporâneos. $\mathrm{O}$ artigo busca provar que há valores, significados e mensagens produzidos pela cultura da mídia, que induzem o telespectador à reflexão crítica e não apenas ao puro entretenimento e à conformidade social.

Palavras - Chave: mídia contemporânea; produto cultural

\begin{abstract}
This essay consists of an analysis of the movies "Lord of War," "Blood Diamond" and "Syriana"; three huge Hollywood productions that are cultural products of the contemporary media frankly inserted into the logic of the marketplace. Its content, however, despite being appealing in nature, presents a number of different meanings. Inspired by the British cultural studies and the multi-perspective analysis of Douglas Kellner, who makes use of "historical resources and social and communications theories," this work proposes a different vision of contemporary mass audience cultural products. The essay intends to prove that, indeed, values, meanings and messages are produced by the media culture that induce viewers to evolve critical thought, rather than only meant to provide pure entertainment and social conformity.
\end{abstract}

Key words: Cultural product; contemporary media; polissemic messages

\footnotetext{
${ }^{1}$ Artigo apresentado no III Intercom Júnior - Jornada de Iniciação Científica em Comunicação

${ }^{2}$ Estudante do $5^{\circ}$ período de jornalismo da ECO - UFRJ. Bolsista do Programa de Educação Tutorial da Escola de Comunicação (PET-ECO) da UFRJ. E-mail: jreismn@hotmail.com
} 


\section{Introdução}

Os filmes O Senhor das Armas, Syriana e Diamante de Sangue, assim como tantas outras produções de Hollywood, são produtos culturais de massa. Ou seja, podem ser entendidos como produtos que foram desenvolvidos no âmbito mercadológico e que, por isso, obedecem, em meio a seu processo de criação, a certos padrões e exigências que estão em função dos movimentos do mercado consumidor. Por serem destinados a um público de grandes proporções - as obras não apenas são lançadas em forma de película, nos cinemas do mundo inteiro, como, logo em seguida, são formatadas em DVD e, finalmente, vão para as TVs fechada e aberta - tratam-se de produtos de massa.

O conceito de massa designaria um "conjunto homogêneo de indivíduos que, enquanto seus membros, são essencialmente iguais, indiferenciáveis, mesmo que provenham de ambientes diferentes, heterogêneos e de todos os grupos sociais." (WOLF, MAURO. 1995) Pode-se dizer que a sociedade de massa é conseqüência do processo de industrialização que, ao padronizar e intensificar a produção, contribuiu para uma homogeneização e, logicamente, para uma perda de individualidade do sujeito moderno. O produto cultural de massa está, portanto, formatado de maneira adequada a padrões e exigências convencionais e, preferivelmente, conservadoras, de modo que sua aceitação seja mais ampla. Ainda que consista numa obra artística ou ficcional, como é o caso dos filmes analisados, não deve ser visto como simples fruto de inspiração de um artista, escritor, etc., mas como uma mistura de forças criativas, estas relacionadas aos desejos do artista, e mercadológicas. A própria expressão "produto cultural" já remete a esse sincretismo de forças, uma vez que o termo 'cultural' representa o que está enraizado nos costumes e no poder de criação humanos, enquanto que 'produto', ao remeter à noção de mercadoria, definiria a obra como um elemento constitutivo do sistema capitalista.

Como os produtos em análise pertencem ao meio cinematográfico, cabe, nesse ponto, a inserção de uma fala do pesquisador Douglas Kellner, da Universidade do Texas (EUA) que, de forma objetiva, define a natureza da produção cultural na mídia:

\footnotetext{
A cultura da mídia é industrial; organiza-se com base no modelo de produção de massa e é produzida para a massa de acordo com tipos (gêneros), segundo fórmulas, códigos e normas convencionais. É, portanto, uma forma de cultura comercial, e seus produtos são mercadorias. (KELLNER, 2001, p. 9)
}

Tal segmento lembra que a cultura da mídia é produzida seguindo uma espécie de linha de montagem, em analogia à forma como a maioria dos produtos industriais são 
confeccionados. O problema está no fato de que as criações culturais são muito mais complexas do que um simples produto, este limitado à sua concretude e função específica. E, se a motivação para a elaboração de uma obra cultural, seja essa um filme, novela ou livro, for a obtenção de lucro, a perda de um sentido 'bruto' e, principalmente, de uma independência em relação às pressões políticas, sociais e econômicas -, aparentemente, torna-se inevitável. Não por acaso, a chamada era "pós-moderna" é caracterizada por muitos teóricos como um tempo em que as produções artísticas - e aqui me limitarei à televisão e ao cinema, basicamente - são vazias de significado. São caracterizadas por seus fluxos de imagens desconexas e fragmentadas e com precedência sobre a palavra (muitas vezes, a fala não tem relação com a imagem, por exemplo), pois as imagens em si são é que atraem a atenção do telespectador, como se a palavra não fosse necessária para satisfazê-lo. Ele estaria “imerso em uma intensa, porém fragmentária e transitória experiência estética.” (KELNNER, 2001, p. 301)

Em seus estudos da cultura da mídia, Kellner cita um teórico do pós-modernismo, cuja opinião reflete uma visão bastante crítica à cultura da mídia contemporânea:

Para Jameson, o pós-modernismo manifesta a emergência de um novo tipo de platitude e falta de profundidade, um novo tipo de superficialidade no sentido mais literal - talvez o traço formal supremo de todos os pós-modernos. (...) Dizem que tanto os textos quanto os eus pós-modernos carecem de profundidade, são planos, superficiais e estão perdidos na intensidade e na vacuidade do momento, sem substância e significado, sem nexo com o passado. (KELLNER, 2001, p. 301-2)

No entanto, o teórico rejeita essa visão, pois, ao analisar diversos produtos culturais de massa, conclui que as imagens, os fragmentos e as narrativas da cultura da mídia estão saturados de significados, discursos polissêmicos e valores ideológicos freqüentemente contraditórios. A cultura da mídia pode ter conseqüências reacionárias, ao idealizar "os valores e instituições contemporâneas, exaltando, portanto o modo de vida vigente" (KELLNER, 1982), veiculando mensagens, tanto por meio de telejornais, quanto por meio de obras de ficção, que visam a manter a ordem social, atuando como porta-vozes do poder. Mas Kellner percebe como essa mesma cultura pode gerar conseqüências progressistas ao oferecer recursos que fortalecem os indivíduos em sua oposição a esse tipo de sociedade (KELLNER, 2001). A própria mídia veicula críticas - inclusive direcionadas a si mesma - e valores contraditórios, muitos dos quais se chocam com os valores e ideais das classes dominantes.

Enquanto a cultura da mídia promove os interesses das classes que possuem e controlam os grandes conglomerados dos meios de comunicação, seus produtos também participam dos conflitos sociais entre grupos concorrentes e veiculam posições conflitantes, promovendo, às vezes, forças de resistência e progresso. Conseqüentemente, a cultura veiculada pela mídia não pode ser rejeitada como um instrumento banal da ideologia dominante, mas deve ser interpretada e 
contextualizada de modos diferentes dentro da matriz dos discursos e das forças sociais concorrentes que a constituem. (KELLNER, 2001, p. 27)

Seguindo essa linha de pensamento desenvolvi este artigo, que tem o objetivo de explicitar e comentar os muitos significados embutidos nas produções da mídia contemporânea, que expressam e confirmam valores ideológicos vigentes e, ao mesmo tempo os criticam. Procurei mostrar, ao longo do ensaio, como os filmes analisados têm o mérito de colocar o espectador para pensar, não consistindo apenas no puro entretenimento e no vazio de sentido. O potencial progressista e mobilizador dessas produções também é destacado, contrariando a idéia de que a cultura da mídia é apenas superficial e alienadora.

\section{Contexto Histórico}

Sem dúvida, após os atentados de 11 de setembro de 2000, uma nova ordem mundial começou a ser desenhada. As fronteiras geográficas, sociais e econômicas que, com o processo de globalização e desenvolvimento dos meios de comunicação, até então vinham se desintegrando, começam a se restabelecer, ainda que sob outros formatos, principalmente quando se trata das relações entre Ocidente/Oriente Médio, ou mundo Cristão/Muçulmano. A xenofobia ressurge com forças, como conseqüência das tentativas de reafirmação de identidades (nacionais, religiosas, etc.), que se chocam a todo momento com o intercâmbio constante das mais diversas culturas, propiciado pelo avanço das tecnologias da informação e convergência de novas mídias.

Violência, fome, miséria, desigualdade sócio-econômica, novas doenças, desastres ambientais e previsões distópicas são cada vez mais recorrentemente noticiados pela imprensa, intensificando o sentimento de descrença e, num movimento paralelo, acentuando o individualismo e o isolamento entre os sujeitos. Esses são "tranqüilizados" com doses diárias de entretenimento por meio do consumo, tanto de bens materiais quanto de produtos abstratos tais quais os produtos culturais.

Regiões como o Oriente Médio e o continente africano que, atualmente estão entre as mais conturbadas do mundo, enfrentando guerras - cuja aparente motivação étnica e religiosa ofusca os interesses políticos e econômicos que estão por trás de tais conflitos -, miséria e doenças, são exemplos do contraste entre as riquezas naturais e a pobreza, característico das nações “subdesenvolvidas.” Não por acaso, esses lugares são o 'palco' das produções em análise, que retratam as relações de dominação e exploração estabelecidas entre o "primeiro" e o "terceiro" mundos. 
Os filmes analisados neste trabalho parecem reproduzir o ambiente quase caótico que estamos vivendo, nas mais diferentes esferas sociais, enfocando o sistema político atual, este representado como falido e sujeito à corrupção sem limites. Apresentam críticas contundentes ao modus operandi característico desse universo político, expondo uma espécie de relação de interdependência entre as esferas legal e ilegal e atentando para o fato de que sua coexistência é inerente à natureza da ordem social vigente.

\section{Descrição dos Filmes}

A escolha desses três filmes para esta análise se deve ao fato de que são produções recentes, produzidas e veiculadas nos últimos dois anos e pertencentes a uma mesma linha de produção, não apenas por serem obras dos mesmos estúdios, mas por abordarem temas delicados, polêmicos, e sob uma perspectiva diferente, que permite uma leitura alternativa de problemáticas atuais, através da diversidade de significados expostos aos espectadores.

As produções analisadas são tipicamente Hollywoodianas: contam com atores de peso, e com alta tecnologia áudio-visual, proporcionando imagens, fotografias, cenários, sons e efeitos especiais extremamente apurados. Cenas de violência e ação também são constantes, o que reforça esse estereótipo.

O filme O Senhor das Armas (2005) tem como protagonista um traficante de armas internacional, cuja atuação é apoiada pelo próprio governo norte-americano. A produção, rodada principalmente na África, estabelece uma relação entre o tráfico de armas, as guerras civis nesse continente, e a economia de países desenvolvidos como os EUA.

Em Syriana, um agente da CIA nota que os interesses políticos sobrepõem-se ao trabalho realizado pela agência, ao investigar um caso envolvendo a indústria do petróleo. Esse filme retrata as disputas entre as grandes corporações que brigam pelos poços de petróleo no Oriente Médio. Representando o interesse de tais corporações, os políticos norteamericanos articulam manobras, muitas vezes, ilegais para atingir os objetivos das empresas.

Já Diamante de Sangue trata da questão da exploração de diamantes no continente africano e os conflitos ocasionados pelas disputas por minas. Milhares de africanos morrem ou são postos para trabalhar nessas minas, sob condições desumanas. São obrigados a procurar por pedras de diamante que nunca verão na vida, já que essas são exportadas para os países de primeiro mundo ou são utilizadas como moeda de troca em guerras civis.

\section{Análise dos Filmes}


Em O senhor das Armas, destaca-se o modo como foi abordada a questão do tráfico de armas e das guerras. Há, na trama, muitas críticas (ainda que não escancaradas) ao sistema capitalista e à peça mais importante desse sistema: os EUA, berço dos mesmos estúdios onde foi desenvolvida tal produção.

Um dos cartazes desse filme, que consiste basicamente numa foto do traficante (Yuri), enquadra, como numa foto $3 \mathrm{X} 4$, o seu rosto e o colarinho de seu terno. Tanto sua pele e cabelo quanto sua roupa são feitos de munição, como se tivessem sido confeccionados a partir de balas de fuzis, identificando a ligação do personagem com as armas e, conseqüentemente, com a violência. O terno, símbolo de prosperidade e status na sociedade capitalista, representa a riqueza do traficante, o que pode ser entendido como uma ligeira crítica ao sistema capitalista, aludindo ao fato de que o crime também representa uma das vias possíveis para o enriquecimento ${ }^{3}$.

As inúmeras balas de armas que (des)figuram a imagem do personagem (Yuri) remetem a uma fragmentação desse sujeito, que, no próprio filme, enfrenta momentos de crise, mais relacionadas com sua vida conjugal do que com o caráter de sua profissão, uma vez que o traficante se apóia firmemente em seu discurso quanto à questão da ideologia. Para ele, é preciso não se prender à ideologia, a fim de que se possa realmente triunfar nos negócios (na vida), por isso negocia com qualquer nação, amiga ou inimiga dos EUA. Além disso, ele próprio se entende como uma peça importante dos mecanismos do sistema capitalista (como eu mencionarei depois), o que justificaria - aparentemente - o seu trabalho. Essa posição também é adotada pelo traficante de diamantes do filme Diamante de Sangue, que diz oferecer um serviço, pois vende algo que o mundo quer e por um preço barato. "Fazemos negócios juntos", ele afirma em certa cena.

Se, por um lado, a fragmentação do personagem sugere que a ilegalidade - marco de sua forma de atuação profissional - não é sadia ou correta, por outro, a maneira como o traficante lida com o fato de sua atividade ser ilícita, coloca em jogo algumas noções éticas e morais de nossa sociedade. Pois esse personagem, em diversos momentos, apresenta argumentos lógicos e, até certo ponto, bem convincentes, quanto à questão do tráfíco de armas, levando o público a identificar-se com sua figura (que é também dotada de elementos carismáticos), o que contribuiria para uma melhor aceitação de suas idéias.

\footnotetext{
${ }^{3}$ Pode-se relacionar a motivação para tal crítica aos inúmeros casos de corrupção e impunidade - principalmente quando se tratam de pessoas ricas e poderosas - que são incessantemente noticiados pela mídia do Brasil e do mundo.
} 
O início de $O$ Senhor das Armas é bem significativo. Mostra-se a trajetória de uma bala, desde sua confecção, distribuição e venda (tudo nos conformes da lei) até que, em dado momento, a bala chega às mãos de um 'rebelde' (ou bandido, terrorista, marginal, etc.) que carrega sua arma, e depois atira, matando um jovem que aparentava ter uns 17 anos. Essa rápida seqüência de imagens pode ser considerada um verdadeiro resumo do filme, pois revela uma perturbadora ligação do legal e o ilegal e as conseqüências de tal associação.

O tráfico de armas, tema do filme, é um exemplo prático da questão acima descrita. Trata-se de uma atividade das mais enriquecedoras do mundo, representando uma forma de se imprimir 'fôlego' nas economias de diversos países. E como um dos principais agentes dessa atividade, o filme aponta os Estados Unidos da América, maior produtor e exportador de armas do planeta, fomentando e alimentando guerras.

O filme Syriana revela as manobras políticas dos EUA para manterem relações comerciais favoráveis com o Irã. Para isso contam com o auxílio da CIA, assassinando, reprimindo e até provocando guerras. Em meio às disputas pelo petróleo, políticos, empresários, entre outros, apropriam-se das riquezas geradas por tal exploração, enquanto cidadãos sofrem as conseqüências dos intensos conflitos ocasionados pelo choque de interesses das mais altas esferas do poder. O que se assemelha à situação do tráfico de armas, já que a riqueza gerada por essa atividade depende da manutenção de conflitos que prejudicam milhões de pessoas.

Logo no início desse filme, um dos personagens diz, referindo-se a uma das empresas norte-americanas que detêm diversos poços de petróleo no Oriente Médio: "Esta será, em breve, a empresa mais rica dos Estados Unidos da América, desde que continue o caos no Oriente Médio". Ou seja, está aí implícito que o desenvolvimento e a prosperidade dos EUA dependem, pelo menos em algum nível, dos contínuos problemas que assolam o Oriente Médio (que acabam favorecendo as negociações para os norte-americanos). Trata-se da lógica do capital, movendo interesses e provocando uma série de problemas que são explicados de diversas formas pelos governantes, telejornais, imprensa escrita, etc., mas raramente da maneira como esses filmes os abordaram.

E é essa lógica que também se expõe em Diamante de Sangue, cujo título já é bastante representativo quanto panorama atual da exploração de pedras preciosas, principalmente na África. Esse filme mostra como as condições de trabalho nas minas são desumanas, os salários, miseráveis, e as disputas, intensas. Trata-se de mais uma situação, tal qual o tráfico de armas e a exploração de petróleo, em que a riqueza gerada e a própria distribuição do recurso depende de redes de corrupção, políticas agressivas e prejudiciais ao povo, bem como 
de conflitos armados. O filme também chama a atenção para o fato de que o continente africano é praticamente esquecido e, sua situação, quase que banalizada pela mídia em geral, a qual produz imagens comerciais de pessoas esqueléticas, da miséria e violência locais. Isso fica claro quando uma das personagens coadjuvantes, que é jornalista, diz, ao avistar o segundo maior campo de refugiados africanos, com mais de um milhão de pessoas: "Talvez isso mereça um minuto na CNN, entre a seção de esportes e a previsão meteorológica."

Há também uma outra crítica importante direcionada à mídia, em Diamante de Sangue. Ao ser questionado pela jornalista, o traficante (protagonista do filme) lembra que a imprensa também ajuda a vender 'diamantes de sangue' (diamantes provenientes das zonas de conflito), ao negociar o espaço nos jornais com anunciantes dessas pedras, mesmo no caso de revistas politicamente corretas. $\mathrm{O}$ que reforça a idéia de que essa atividade - mesmo quando diretamente associada aos conflitos na África - está realmente inserida na economia de diversos países do mundo.

Além da contradição básica de que esses filmes chamam a atenção para as contravenções e atividades ilícitas que são interessantes à economia de países desenvolvidos, como os EUA, criticando 'suas próprias origens', são produções que, exatamente por essa forte crítica apresentada, estão carregadas de sentidos e valores ideológicos, levando a um processo diversificado de construção e interpretação da informação. Por essa razão, a possibilidade dos telespectadores de refletir e compreender mensagens de uma maneira mais abrangente é maior, abalando, portanto, a ‘certeza pré-fabricada' pelo discurso ideológico ${ }^{4}$.

É preciso entender que a lógica do mercado, ou melhor, do capital, é que dita e molda a cultura contemporânea. Não há como escapar disso. A indústria cultural, que representa a apropriação dos discursos, manifestações e elementos culturais pelo Grande Capital, vai engolindo todas as produções culturais; do 'brega ao chique', da 'palhoça à bossa nova', do artesanal ao industrializado. É, portanto, natural que o objetivo de muitos artistas, ainda que empreguem criatividade, sensibilidade e um toque pessoal em suas obras, seja o de vender e satisfazer os interesses e desejos de seu público, que é então visto como consumidor em potencial. Há de se garantir uma demanda para o produto cultural, de se conquistar um segmento de mercado para que a próxima criação tenha sucesso garantido.

Em função da incessante busca da satisfação do espectador/consumidor, os profissionais envolvidos com a criação desenvolvem padrões e modelos e utilizam 'fórmulas'

\footnotetext{
${ }^{4}$ Para Stuart Hall, certos códigos parecem ser naturais, por serem aprendidos muito cedo, alcançando uma 'quase universalidade', o que produziria o efeito ideológico de encobrir as práticas de construção de discursos atualmente. (Hall. 2003.p. 393)
} 
para garantir a venda, o que poderia levar à superficialidade e à perda de sentidos do produto cultural de massa, que ficaria limitado a essa função primordial de vender e gerar lucros.

Adorno já identificava como conseqüência da industrialização e padronização cultural, o que chamava de "pseudo individuação", que seria a simulação da novidade a partir da mistura de uns poucos elementos novos que servem mais para disfarçar a mesmice do que para inovar realmente. O trecho a seguir ilustra, brevemente, a problemática apontada pelo autor da Escola de Frankfurt:

\begin{abstract}
Por pseudo-individuação entendemos o envolvimento da produção cultural de massa com a auréola da livre escolha ou do mercado aberto, na base da própria estandartização. Os improvisos, os desvios, as inovações, são trazidos de volta à norma e oferecidos como possibilidades desta. Os efeitos previstos fornecem segurança à audição e ao consumo; garantem a sensação de satisfação, de proximidade (...). A repetição garante a aceitação do material, estendendo à difusão o que já foi repetido no processo de produção. (DIAS, MARCIA TOSTA. 2000, p. 48)
\end{abstract}

É muito comum em filmes e novelas, por exemplo, a utilização de fórmulas e modelos, baseados em produções anteriores bem sucedidas, para garantir o sucesso de novas produções. A noção do clichê faz parte dessa estratégia. Essa ferramenta, por assim dizer, nada mais é do que uma forma de representação, isto é, a produção de uma imagem, que é continuamente utilizada, tornando-se um lugar-comum, um verdadeiro "chavão".

Uma conseqüência notável desse modo serializado de se produzir arte, que se deve à necessidade de se manterem ou aumentarem as vendas, seria o medo de errar ao tentar abordagens novas, em função do risco de, ao fugir das convenções, desagradar à massa de consumidores. Esse fenômeno pode contribuir, inclusive, para uma limitação e submissão das manifestações artísticas ao modelo de vida vigente e valores ideológicos hegemônicos, à medida que incentivaria uma produção artística cada vez mais convencional e conservadora.

No entanto, as produções em análise retratam a dinâmica de atividades que, ilícitas ou não, estão relacionadas a conflitos e mazelas sofridas pelas populações do mundo, como as guerras civis que ocorrem há décadas na África. O Senhor das Armas mostra como é interessante à indústria bélica a manutenção dos conflitos armados, principalmente num continente pobre, negro e esquecido pela globalização, ou seja, "totalmente dispensável". Além disso, o filme possibilita o entendimento de que a miséria e a fome também são resultados das guerras - e, portanto, da produção e tráfico de armas -, que desarticulam qualquer tentativa de reorganização social, em virtude de toda a violência promovida.

Pode-se estabelecer uma relação do tráfico de armas com os conflitos em áreas de exploração de diamantes na África, situação que é retratada no filme Diamante de Sangue. 
Essas pedras preciosas, que são compradas por altos preços na Europa e nos EUA, são usadas, como mostra o filme, para se comprar armas e financiar guerras. Em uma das primeiras cenas do filme, um político lembra, durante uma conferência internacional, que os EUA consomem dois terços da produção mundial de diamantes e que, portanto, devem se esforçar para não importá-los direta ou indiretamente de zonas de conflito.

A estória revela como a política, nessas regiões, está atrelada aos interesses sobre os diamantes e como as comunidades locais são afetadas pela exploração de pedras preciosas que nunca irão usar em benefício próprio. Os interessados são as empresas e consumidores estrangeiros e, do outro lado, os governantes, 'rebeldes' e traficantes africanos. O protagonista do filme, por exemplo, é um traficante de diamantes sul-africano, que é contratado por uma grande empresa inglesa para lhe fornecer pedras preciosas por preços mais baratos. E o próprio governo Inglês tem conhecimento dessa movimentação ilegal.

Em Syrinana, a idéia básica é que as relações entre as instituições, instâncias políticas, empresas e o Oriente Médio, são estabelecidas de acordo com as negociações relativas ao petróleo. Pode-se dizer que esse tipo de conduta política não tem motivações ideológicas (ou que visem ao bem-estar social), mas puramente mercadológicas, e um forte argumento para isso é que países de primeiro mundo vítimas de terrorismo são os mesmos que financiam tal atividade ao enriquecer - com quantias astronômicas - os 'sheiks' e governantes árabes, como mostra o filme.

É importante mencionar que os governantes e referências políticas dos países africanos e do Oriente Médio são, nessas produções, representados como terroristas (ou possíveis terroristas), no caso árabe ou ditadores que matam indiscriminadamente todos aqueles que pertencem a outras tribos e/ou religiões, na África. Tais governantes desfrutam das riquezas proporcionadas pela abundância de pedras preciosas e petróleo e, para concentrar a renda e manter a população e inimigos sob controle, utilizam seus exércitos "particulares" terroristas, rebeldes ou as próprias forças armadas, que também são acionadas em função do interesse por esses recursos - para garantir sua prosperidade.

É possível que essa visão dos filmes seja um tanto tendenciosa, uma vez que, ao retratar os líderes de tais nações como tiranos, poderiam estar, de certo modo, visando a justificar uma hipotética intervenção militar por parte dos países ricos (como os EUA), assim como ocorreu no Iraque. Aliás, o próprio fato de todos esses conflitos e situações caóticas se desenrolarem nessas regiões do planeta - indiferentes ou preocupantes aos países de primeiro mundo - já pode ser entendido como uma motivação para intervenções, assim como na segunda metade do século XIX, alegações como a "superioridade do homem branco europeu" 
justificavam o domínio sobre a África. Percebendo a situação representada dessa forma, podemos inferir que, nesse caso, o sentido veiculado é favorável às estruturas hegemônicas mundiais, confirmando valores idealizados por essas forças.

Em “O Senhor das Armas", mostra-se que os ditadores africanos necessitam de muitos armamentos, como a AK-47, apontada no filme como uma das metralhadoras mais mortais desenvolvidas pelo homem (já matou muito mais pessoas que qualquer arma de destruição de massa, estas alvos das maiores operações anti-armas, financiadas pelos mesmos governos que produzem, aos milhares, a AK-47). Os países ricos e poderosos, por sua vez, precisam de uma via de escoamento para o excedente de sua produção bélica. A porção de armamentos que não pode ser legalmente vendida e exportada por razões de protocolo, acaba nas mãos de traficantes que, como o filme deixa entender, são uma espécie de empregados sem carteira assinada dos governos. Essa questão fica clara no momento em que o filme atinge seu clímax. Trata-se da parte em que o traficante (Yuri), interpretado por Nicholas Cage, é capturado pelo policial do Dpto. Anti-drogas dos EUA (Ethan Hawke). Sentados frente a frente em uma mesa, na delegacia, o traficante, extremamente calmo, começa a explicar porque, dentro de minutos, será liberado. Ele diz que um homem irá bater à porta e chamar o policial para conversar. Esse homem dirá que fez um excelente trabalho, capturando-o, mas que ele terá que ser solto. Nesse ponto, o traficante diz que o presidente dos Estados Unidos da América ("que produz e vende mais armas em um dia do que eu em um ano", de acordo com suas palavras) precisa de gente como ele para fazer o trabalho sujo, ilegal e, que não pode ser executado pelo Governo - oficialmente. O criminoso é então solto por uma autoridade militar - na cena, o homem que o libera está fardado -, e ainda exige ser pago pelo inconveniente, o que reforça a noção de que é um empregado do Governo.

A descrição dessa cena teve como objetivo ratificar a afirmação de que esse filme, assim como os outros dois, embora seja uma produção cultural de massa contemporânea, francamente inserida na ordem mercadológica, apresenta, paradoxalmente, uma profunda crítica ao modus operandi do sistema capitalista e ao país símbolo do capitalismo5: a economia norte americana, segundo o filme, estaria também arraigada a atividades ilícitas, como o tráfico de armas, o qual possibilita um escoamento da produção bélica excedente.

\footnotetext{
${ }^{5}$ Não pretendo avaliar as conseqüências de tais críticas em nível prático na sociedade, até porque se as mesmas levassem, necessariamente, todas as pessoas a se mobilizarem e organizarem uma revolução, por exemplo, um roteiro como esse não teria forças para constituir filmes de tais proporções, com tamanha repercussão. Mas penso que essas críticas são importantes no sentido de levar as pessoas a pensar e a conhecer mais a fundo o sistema de que fazem parte.
} 
Douglas Kellner já havia formulado semelhante raciocínio quando, ao analisar a série de TV americana "Miami Vice", observou que a série - caracterizada por críticos do pósmodernismo como sendo uma produção tipicamente 'pós-moderna', por seu formato de vídeo-clipe, imagens desconexas e predominantes sobre a palavra, etc. -, aponta a entrada de drogas provenientes de países de terceiro mundo como uma forma dos mesmos pagarem parte de sua dívida externa. Ou seja, a economia americana estaria dependendo de uma atividade ilegal para se manter. É exemplar o fato de a mesma série apresentar o mundo do tráfico de drogas como uma espécie de sonho capitalista, de lucro alto e fácil, uma vez que os personagens que representam grandes chefes do tráfico estão sempre muito bem vestidos, com mulheres e automóveis possantes e freqüentam as melhores danceterias de Miami.

É interessante observar, a partir do que os filmes revelam a respeito da relação dos governos e o tráfico de armas, de diamantes e as manobras antiéticas e/ou ilegais na exploração de petróleo, isto é, do oficial e legal com o ilegal e ilícito, como uma parte não 'sobrevive' sem a outra. Pelo menos no contexto do sistema capitalista. O que vai de encontro a um tradicional dilema: pode a lei existir sem o crime, a enfermidade sem o poder de cura ou, generalizando, o bem sem a presença do mal? ${ }^{6}$

Uma cena do filme Syriana é bastante significativa a esse respeito, expressando a complementaridade existente entre a lei e a contravenção. Um dos advogados de uma grande empresa petrolífera, detentora de boa parte dos poços de petróleo no Oriente Médio, ao ser interpelado por um investigador, chega a citar Milton Friedman, ganhador do prêmio Nobel: “A corrupção é a intrusão do Governo via regulamentação." E continua: "A corrupção é a nossa proteção. É o que permite que tenhamos um lucro fabuloso. É o motivo pelo qual nós GANHAMOS.” Não se pode deixar de enfatizar o valor dessa última frase, considerando que, principalmente para a sociedade norte-americana, a figura do looser é uma das que mais depreciativas ${ }^{7}$. Ou seja, o sentido veiculado nesse caso é bastante explícito e, em certa medida, desconstrói o discurso da mídia quanto ao problema da corrupção na política.

Uma das principais idéias que são veiculadas por essas produções é que, se as relações humanas (de todo o tipo: políticas, econômicas, sociais, etc.) continuarem a se basear

\footnotetext{
${ }^{6} \mathrm{O}$ autor francês Jean Baudrilard já se pronunciava a esse respeito: "O social funciona sobre a base da disfunção do acidente, do catastrófico, do irracional (...). Dizer que tudo isso pode ser exorcizado, erradicado, significa acreditar numa racionalidade absoluta, é insistir numa perspectiva religiosa de salvação"; "Não existe esse ponto ideal e perfeito, esse ponto de chegada para a história. Não há o bem sem o mal e vice-versa. Um está ao lado do outro." (Baudrillard, Jean, 1991)

7 'Looser' significa 'perdedor'. A sociedade norte-americana é extremamente competitiva, o que é comprovado em seu desempenho como potência mundial e a imagem do 'perdedor' é bastante estigmatizada pelos norte americanos.
} 
estritamente na lógica do capital, sendo motivadas pela perspectiva do acúmulo de riquezas, a desigualdade e outros males que assolam grande parte da humanidade perdurarão. Pois, o sistema como um todo está atrelado a atividades ditas irregulares, cujos sintomas se traduzem na forma de violência, pobreza, miséria, etc.. Mas em verdade, essas aparentes 'falhas do sistema’ são um mal necessário.

"Mal necessário". Essa foi a expressão utilizada pelo traficante Yuri (de O Senhor das Armas) para se auto definir, frente ao policial que o havia prendido. Ele representa a parte podre do sistema que, nos noticiários aparece sendo combatida pelos órgãos governamentais mas que, por trás da moral burguesa, longe dos olhos públicos, atua na brecha do sistema convencional - cobrindo os espaços aos quais a luz da legalidade não pode chegar.

\section{Conclusão}

Os filmes analisados têm, portanto, o mérito de levantar questões delicadas e pôr o telespectador para pensar a respeito delas. Suas imagens de violência são bem marcantes e, ainda que façam parte de uma estratégia para prender a atenção do telespectador, os filmes não se resumem apenas a essa violência, pois elas remetem a uma problemática mais complexa, havendo, portanto, significados por trás de sua veiculação. Isto é, não são imagens vazias de sentido. As produções não são apenas entretenimento. Consistem num verdadeiro estudo sobre a relação da lógica do capital, a violência e a contravenção

Ainda que, em alguns momentos, os filmes possam ser confundidos com os tipos convencionais de Hollywood, ao assumir padrões, clichês ou estereótipos recorrentemente utilizados pela indústria cinematográfica norte-americana, eles se diferem significativamente dos mesmos, ao elaborar um discurso contundente e até ameaçador às estruturas sociais vigentes. Ainda assim, conseguiram angariar recursos e ser desenvolvidos por uma grande produtora, um dos componentes básicos da Indústria Cultural, a qual cumpre um importante papel na manutenção do sistema capitalista. Esse sistema não é coeso ou monolítico, sendo possível, através da articulação de idéias e pensamentos diversos, a produção de significados plurais e até contraditórios. Desde que a produção seja bem sucedida financeiramente, gerando lucro, para, assim, encaixar-se na lógica de mercado em que está inserido todo o universo hollywoodiano.

A cultura da mídia deve, por conseguinte, ser vista como um terreno em que se chocam valores, ideais e sentidos plurais e contraditórios e não apenas como um meio de confirmação e massificação da cultura hegemônica. 
“As lutas concretas de cada sociedade são postas em cena nos textos da mídia, especialmente na mídia comercial da indústria cultural, cujos textos devem repercutir as preocupações do povo, se quiserem ser populares e lucrativos." (KELLNER, 2001, p. 32)

O pluralismo de sentidos a que me refiro no título deste trabalho está relacionado não só ao fato de que os filmes analisados, apesar de sua natureza industrial e "pós-moderna", são compostos por imagens e roteiro carregados de críticas e significados diversos, mas por induzirem a uma leitura ampla e à desconstrução de mitos sociais, estes muitas vezes confirmados pela atuação e influência da mídia. Além disso, seus textos e visões críticas destoam do discurso da própria imprensa, revelando o que os jornais, estes dependentes de concessões e financiamentos governamentais, muitas vezes, não dizem.

A afirmação de Douglas Kellner de que a cultura da mídia contemporânea consistiria numa "falta de dominante cultural", e que "diferentes formas da cultura da mídia desempenham papel fundamental (...) na conformação de pensamentos e comportamentos" (Kellner, 2001, p. 304), reflete bem o caso dos filmes analisados que, sob uma roupagem tipicamente comercial, não apenas entretêm ou alienam, mas informam, criticam e despertam.

\section{Referências Bibliográficas}

Kellner, Douglas. A Cultura da Mídia - Estudos Culturais: Identidade Política entre o Moderno e Pós-Moderno. EDUSC: São Paulo, 2001.

Dias, Márcia Tosta. Os Donos da Voz: indústria fonográfica brasileira e mundialização da cultura. São Paulo: Boitempo, 2000.

Mattelart, Armand et Neveu, Érik. Introdução aos Estudos Culturais. Parábola Editorial: São Paulo - SP. 2004.

Hall, Stuart. Da Diáspora - Identidades e Mediações Culturais. Editora UFMG: Belo Horizonte, MG. 2003.

Adorno, Theodor et Horkheimer, Max. Dialética do Esclarecimento. Jorge Zahar Editora, 1985

Wolf, Mauro. Teorias da Comunicação. Lisboa, 1995

Baudrillard, Jean. Simulacros e Simulação. Relógio d’água. 1991 